\title{
IMPORTÂNCIA DA PESQUISA NA FORMAÇÃO DOCENTE PARA A PRÁTICA PEDAGÓGICA REFLEXIVA
}

\section{MIDIAM SILVA PINHEIRO}

Instituto Federal do Espirito Santo

E-mail: midiamster@gmail.com

\section{MARIZE LYRA SILVA PASSOS}

Instituto Federal do Espirito Santo

E-mail:marize@ifes.edu.br

\section{ISAURA ALCINA MARTINS NOBRE}

\section{Instituto Federal do Espirito Santo}

E-mail: isaura@ifes.edu.br

\section{RESUMO:}

Atualmente muito se fala em preparar o aluno para o mundo moderno e, para que isso ocorra, fazse necessário analisar a influência que a pesquisa tem na vida do docente. Os sujeitos deste estudo foram os alunos do curso de Pós-graduação Latu Sensu em Informática na Educação do Instituto Federal do Espírito Santo. A pesquisa pautou-se numa abordagem qualitativa, de natureza exploratória e descritiva, e teve como procedimento técnico o levantamento de dados, por meio de aplicação de um questionário com o propósito de verificar o quanto a elaboração do Trabalho de Conclusão de Curso influenciou na prática docente por meio do desenvolvimento da pesquisa. Dessa forma, este trabalho colaborou na compreensão do quanto a pesquisa docente para prática reflexiva é importante para um professor, revelando os obstáculos encontrados como falta de tempo, materiais e infraestrutura em geral para a execução da mesma.

\section{PALAVRAS-CHAVE:}

prática docente. professores reflexivos. pesquisa.

\begin{abstract}
:
Today there is much talk in to prepare the student for the modern world and, for this to occur, it is necessary to analyze the influence that the research has in the life of the Faculty. The subjects of this study were students of the Postgraduate in Informatics in Education from the Federal Institute of Espírito Santo. The research was guided in a qualitative approach, exploratory and descriptive, and had as technical procedure the survey, the questionnaire had the purpose of verifying how the development of the final task of the course influenced the teaching practice. This work helped in the understanding of how the research faculty is important for a teacher, revealing the obstacles encountered as lack of time, material and infrastructure in general for the execution of same.
\end{abstract}

\section{KEYWORDS:}


teaching practice. reflective teachers. research.

\section{INTRODUÇÃO}

O mundo está em constantes mudanças, e diante disso nos deparamos com um desafio que é formar cidadãos críticos para a sociedade. Observamos então a necessidade de uma formação adequada para que os professores saiam do método tradicional de ensino, e evolua para um novo patamar, o de professor pesquisador reflexivo.

Neste sentido, há necessidade das instituições formadoras, não apenas formar professores pesquisadores, mas desenvolver a capacidade reflexiva dos mesmos. 0 aluno que elabora um Trabalho de Conclusão de Curso em uma especialização passa por várias etapas de pesquisa, sobre o quê pretende pesquisar e quais objetivos, o porquê pesquisar e que contribuição essa pesquisa trará e quais resultados ele pretende alcançar. Diante disso ele passa a refletir sobre o seu trabalho, o seu dia a dia e a reunir dados para a elaboração de sua pesquisa. Essa atitude reflexiva diante da pesquisa e que precisa estar refletida no cotidiano de sua sala de aula.

A sociedade está mudando e a escola também deve acompanhar esse processo. Na formação do professor é essencial a pesquisa, porque por meio dela o professor avalia o local pesquisado, bem como métodos para realizar o trabalho. E é a combinação entre teoria e prática que se faz um professor pesquisador reflexivo capaz de investigar a sua prática e criar novas maneiras pedagógicas.

Nesse contexto, este projeto tem como relevância mostrar que a pesquisa na formação docente, bem como a reflexão sobre ela, colabora para a prática pedagógica. Iniciou-se observando que a formação é imprescindível para os professores. Visto que os professores precisam se capacitar para fazer do ambiente escolar um local rico, com novos recursos que facilitem a aprendizagem e a torna mais prazerosa. 
Diante desse cenário esta pesquisa foi feita nas turmas de Pós-graduação Lato Sensu em Informática na Educação (PIE) do Instituto Federal do Espírito Santo (Ifes) e, teve como objetivo geral analisar a percepção dos alunos do curso sobre a contribuição da pesquisa desenvolvida a partir do Trabalho de Conclusão de Curso (TCC) no seu processo de aprendizagem e na sua prática docente.

\section{REFERENCIAL TEÓRICO}

A formação dos professores deve ser continuada, pois não basta para os professores saber o conteúdo, faz-se necessário preparar aulas onde a prioridade é o aluno. O que antes era tecnicista, onde o docente apenas reproduzia o que era transmitido pelas universidades, atualmente com as avassaladoras mudanças e transformações que vêm ocorrendo, e a inclusão de tecnologias no dia a dia da sociedade, faz com que os saberes reproduzidos percam rapidamente a validade.

Diante desse quadro temos a necessidade de formar um professor reflexivo para, por meio da pesquisa, ser capaz de aprimorar seu local de trabalho e instigar seus alunos a aprenderem. Para o docente e discente o saber não está terminado.

Freire (1996) destaca que ensinar não é transferir conhecimento e sim preparar meio para que o indivíduo produza ou construa o seu conhecimento. Respeitando o tempo, momento e o local onde ele está inserido. Não adianta olhar para a prática mecanicamente, mas olhar sempre com olhar reflexivo. Segundo este mesmo autor (1996, p.12) “[...] o que é importante é alinhar e discutir alguns saberes fundamentais a prática educativo-crítica ou progressista e que, por isso mesmo, devem ser conteúdos obrigatórios à organização programática da formação docente".

O papel do professor formador vai muito além de quadro e pincel. Conhecer a disciplina, conseguir unir a prática e teoria, questionar o senso comum que é a ideia que todos pensam igual, ou até mesmo abrir mão da experiência que não está 
aprimorando o ensino, por uma metodologia mais adequada para a aprendizagem. Nobre (2013) enfatiza em seu trabalho que:

Em processo contínuo de autoformação cabe ao professor rever suas concepções sobre ensino, aprendizagem, planejamento, interação com alunos, avaliação etc., como forma de construção de conhecimentos e resignificação de práticas. Dessa forma, entendemos que a formação de professores como prática reflexiva, de caráter contínuo, não e sobre a ação, sobre a prática docente, deve ser exercida como forma de promover a autonomia, a partir de uma prática contextualizada, politicamente situada, voltada para a valorização do desenvolvimento de professores e de instituições de ensino (NOBRE, 2013, p. 75)

Observando a necessidade de uma escola preparada para o aluno moderno, é primordial que hajam professores capacitados. Para além das escolas, o sociólogo e antropólogo Philippe Perrenoud (1999) aborda a melhoria na educação e a responsabilidade que a universidade tem para formar professores pesquisadores reflexivos, visto que, a pesquisa deve ser agregada a reflexão, se assim não for os alunos se tornarão apenas técnicos. Para que isso ocorra é necessária a participação de todos no processo, Perrenoud (1999, p. 20) afirma que:

[...] se a universidade é, potencialmente, o melhor lugar para formar os professores para a prática reflexiva e a participação crítica, ela deve, para realizar esse potencial e provar sua competência, evitar toda arrogância e se dispor a trabalhar com os atores em campo.

Um "professor reflexivo" não para de refletir, ele continua progredindo em sua profissão, pois a reflexão transformou-se em uma forma de identidade e de satisfação profissional. Ele conquista métodos e ferramentas conceituais baseados em diversos saberes e constrói novos conhecimentos, os quais são reinvestidos na ação.

Um profissional reflexivo não se limita ao que aprendeu no período de formação inicial, nem ao que descobriu em seus primeiros anos de prática, ele reexamina constantemente seus objetivos, seus procedimentos, suas evidências e 
seus saberes, ingressando em um ciclo permanente de aperfeiçoamento, já que teoriza sua própria prática. Ele faz perguntas, tenta compreender seus fracassos, projeta-se no futuro, decide proceder de forma diferente quando ocorrer uma situação semelhante, estabelece objetivos mais claros, explicita suas expectativas e seus procedimentos (PERRENOUD, 2002).

A pesquisa é um assunto que vem sendo cada vez mais discutido no âmbito escolar, nas secretarias de Educação e na sociedade. Visto que ela faz parte do processo de ensino. Há muitos anos ela tenta ingressar nas escolas, quem retrata essa história da pesquisa são os autores Nascimento, Fernandes e Mendonça (2010, p. 228), que afirmam que "[...] os estudantes deveriam lidar diretamente com materiais e realizar experiências para aprender de modo significativo e que o professor não deveria ser um transmissor de informações, mas orientador do ensino e da aprendizagem".

Freire (1996, p. 14) nos diz que:

Não há ensino sem pesquisa e pesquisa sem ensino. Esses que-fazeres se encontram um no corpo do outro. Enquanto ensino, continuo buscando, reprocurando. Ensino porque busco, porque indaguei, porque indago e me indago. Pesquiso para constatar, constatando, intervenho, intervindo educo e me educo. Pesquiso para conhecer o que ainda não conheço e comunicar ou anunciar a novidade.

Segundo André (2006) o professor formador deve propiciar um ambiente para o aluno aprender a pesquisar, criar situações, fazer perguntas de pesquisa. No envolvimento com a pesquisa ele se sentirá livre para tomar as próprias.

A pesquisa pode tornar o sujeito-professor capaz de refletir sobre a sua pratica profissional e de buscar formas (Conhecimentos, habilidades, atitudes, relações) que o ajudem a aperfeiçoar cada vez mais o trabalho docente, de modo que possa participar efetivamente do processo de emancipação das pessoas. (ANDRE, 2006, p.123) 
Os professores precisam adquirir a formação necessária para associar ensino e pesquisa. Saber ensinar e pesquisar, e trazer isso para sala de aula, ainda é uma grande dificuldade dos professores, porque pesquisar dá trabalho. Carvalho e Pérez (2011, p. 64) propõem a pesquisa na prática e formação do professor:

A iniciação do professor à pesquisa transforma-se assim em uma necessidade formativa de primeira ordem. Não se trata, é claro, de outro componente da preparação à docência, a ser adicionado àquelas que vínhamos considerando, mas de orientar a formação do professor como uma (re)construção dos conhecimentos docentes, quer dizer, como uma pesquisa dirigida.

Os programas de pós-graduação têm crescido muito nas instituições de ensino superior e assim os debates entre ensino e pesquisa tornam-se cada vez mais presentes e, ela traz a compreensão do ensino, a busca por novas técnicas, respostas para determinadas perguntas, compreensão de caminhos.

É necessário haver incentivos para o docente incluir a pesquisa na sua prática diária. Na legislação é abordada a importância da pesquisa no ensino superior, mas há uma grande dificuldade de inclusão, por dificuldades das Instituições de Ensino Superior em se adequar para formar professores pesquisadores. Para André (2012, p. 60), não dá para querer formar pesquisadores sem dar-Ihes condições para tal:

Querer que o professor se torne um profissional investigador de sua prática exige que se pense nas exigências mínimas para sua efetivação, ou seja: e preciso que haja uma disposição pessoal do professor para investigar, um desejo de questionar; e preciso que ele tenha formação adequada para formular problemas, selecionar métodos e instrumentos de observação e de análise; que atue em um ambiente institucional favorável a constituição de grupos de estudo; que tenha oportunidade de receber assessoria técnico-pedagógica; que tenha tempo e disponha de espaço para fazer pesquisa; que tenha possibilidade de acesso a materiais, fontes de consulta e bibliografia especializada. Esperar que os professores se tornassem pesquisadores, sem oferecer as necessárias condições ambientais, materiais, institucionais implica, por um lado, subestimar o peso das 
demandas do trabalho docente cotidiano e, por outro, os requisitos para um trabalho científico de qualidade. (André 2012, p. 60)

A pesquisa acadêmica ou científica não é mais ou menos importante, se ela ajuda ao professor no crescimento profissional, ela deve ser utilizada. A comunidade escolar por vezes acha a pesquisa desnecessária para a escola, visto que ela não resolve todos os problemas, e não tem respostas claras. E os professores pesquisadores reclamam das dificuldades em conseguir acesso às escolas.

\section{METODOLOGIA}

Esta pesquisa será baseada num estudo de cunho misto conforme denominado por Sampieri, Collado e Lucio (1991), uma vez que coleta, avalia e vincula dados qualitativos e quantitativos numa mesma pesquisa. Quanto aos procedimentos técnicos utilizados esta pesquisa foi uma pesquisa de levantamento de dados, ou survey, que na visão de Andrade (2003) é a que se define pela interrogação direta de um grupo específico ou fatos que se deseja conhecer em relação ao problema estudado cujo maior objetivo é descrever uma situação.

Quanto aos seus objetivos esta foi uma pesquisa descritiva, cujo foco foi descrever as características de uma população e permitir a compreensão de comportamentos de diversos fatores que influenciam determinados fenômenos (ANDRADE, 2003). Ela teve um caráter exploratório, pois nela será analisada a percepção que os professores têm em relação às contribuições que o Trabalho de Conclusão de Curso teve em sua formação e na prática pedagógica.

\subsection{SUJEITOS DA PESQUISA}

Essa pesquisa teve como universo os alunos do curso Pós-Graduação Lato Sensu em Informática na Educação (PIE), turmas de 2010 a 2014, que fizeram a disciplina Trabalho de Conclusão de Curso (TCC). Para cálculo da amostra utilizada de forma aleatória simples, que é aquela na qual todos os elementos têm a mesma 
probabilidade de serem selecionados. O cálculo do tamanho da amostra foi baseado na equação 1 ,

$$
n=\frac{N \cdot Z^{2} \cdot p \cdot(1-p)}{Z^{2} \cdot p \cdot(1-p)+e^{2} \cdot(N-1)}
$$

onde $\mathrm{n}$ - amostra calculada; N - população; Z - variável normal padronizada associada ao nível de confiança; $p$ - verdadeira probabilidade do evento e e - erro amostral:

Baseado nesta equação foi obtido os seguintes dados: população (N) igual a 580 (total de alunos que iniciaram a disciplina TCC); nível de confiança (Z) de 90\%; a verdadeira probabilidade do evento $(\mathrm{p})$ foi de $50 \%$ e o erro amostral (e) de $15 \%$. A partir desses dados foi obtido como resultado uma amostra (n) igual ou superior a 29 sujeitos.

Essa pesquisa foi respondida por 34 alunos da PIE que iniciaram a disciplina Trabalho de Conclusão de Curso, então, podemos afirmar que os resultados obtidos têm uma margem de erro de 15\% e um nível de confiança de 90\%.

\subsection{Coleta e ANÁlISE de DADOS}

Para coleta de dados foi elaborado um questionário a partir do google forms e, enviado aos alunos do curso de Pós-graduação em Informática na Educação (PIE) por meio de mensagem no ambiente Moodle. Ele visou obter informações quantitativas e qualitativas sobre o perfil dos sujeitos da pesquisa e sobre a importância da pesquisa em sua formação docente e, o quanto isso influenciou em sua prática reflexiva, em especial, na sua elaboração do trabalho de conclusão do curso.

O questionário teve três partes, na primeira foi levantado o perfil dos professores, na segunda foram levantadas informações quanto a contribuição da 
produção do TCC na formação docente, na terceira foram feita perguntas abertas, sobre tema do TCC, motivação, pontos positivos e negativos e um espaço aberto.

\section{RESULTADOS E DISCUSSÕES}

A seguir serão apresentadas os principais resultados alcançados com esta pesquisa.

\subsection{PERFIL dOS SUJEITOS}

A partir do questionário foi traçado o perfil dos sujeitos dessa pesquisa. Dos 34 professores que responderam ao questionário temos, 2 alunos da turma 2010, 7 alunos da turma de 2011, 7 alunos da turma 2012, 8 alunos da turma de 2013 e 10 alunos da turma de 2014. Quanto ao gênero dos professores pesquisados 65\% é do sexo feminino e $35 \%$ do sexo masculino. A idade dos mesmos varia conforme Tabela 1, onde percebemos que a grande maioria tem entre 31 e 50 anos.

Tabela 1 - Distribuição dos Sujeitos segundo a faixa etária.

\begin{tabular}{|c|c|}
\hline Faixa Etária & Quantidade \\
\hline$>50$ anos & 1 \\
$20-30$ anos & 8 \\
$31-40$ anos & 12 \\
$41-50$ anos & 13 \\
\hline Total Geral & 34 \\
\hline
\end{tabular}

Fonte: Dados compilados da pesquisa.

A formação dos professores pesquisados consiste em: 18\% apenas a graduação e em fase de conclusão do curso PIE. Já 56\% já possuem especialização, 23\% dos sujeitos têm mestrado e 3\% possuem doutorado. De acordo com suas formações todos já tiveram algum contato com pesquisa. Este perfil demonstra que o Curso PIE não é procurado somente por professores que estão cursando a sua primeira especialização. 
Quanto ao tempo de docência têm-se os seguintes dados: 38\% possuem até cinco anos de experiência, 24\% possuem de 6 a 10 anos de experiência, 12\% possuem de 11 a 15 anos de experiência, e 26\% possuem mais de 15 anos de experiência. Já quanto a sua atuação nas redes de ensino percebe-se que 76\% destes trabalham em rede pública de ensino, e dentro deste grupo $47 \%$ são da rede municipal de ensino (Tabela2).

Tabela 2 - Rede de ensino que os professores atuam.

\begin{tabular}{|l|c|}
\hline Rede de ensino que atua? & Docente \\
\hline Não leciono & 1 \\
\hline No momento estou fora da escola & 1 \\
\hline Rede Estadual & 7 \\
\hline Rede Estadual, IFPR (Tutoria à distância) & 1 \\
\hline Rede Federal & 1 \\
\hline Rede Federal, Rede Privada & 1 \\
\hline Rede Municipal & 12 \\
\hline Rede Municipal, Rede Estadual, Rede Privada & 1 \\
\hline Rede Municipal, Rede Federal & 1 \\
\hline Rede Municipal, Rede Privada & 2 \\
\hline Rede Privada & 6 \\
\hline Total Geral & 34 \\
\hline
\end{tabular}

Fonte: Dados compilados da pesquisa - cada sujeito poderia definir mais de uma rede de atuação.

Na Tabela 3 temos os níveis de ensino em que esses sujeitos atuam. Podemos verificar que apenas 25\% atuam em Nível Superior e 75\% estão divididos em Educação Infantil, Ensino Fundamental I, Ensino Fundamental II, Ensino Médio, EAD, Ensino Técnico, e Cursos de aperfeiçoamento. 
Tabela 3 - Nível de Ensino.

\begin{tabular}{|l|c|}
\hline Nível de Ensino & Quantidade \\
\hline cursos aperfeiçoamento & 1 \\
\hline Educação Infantil & 4 \\
\hline Educação Infantil, Ensino Fundamental I & 4 \\
\hline Educação Infantil, Ensino Fundamental I, Ensino Médio, Ensino Superior, Ensino \\
Técnico & 1 \\
\hline Educação Infantil, Ensino Fundamental II, Ensino Médio & 1 \\
\hline Ensino Infantil, Ensino Superior & 1 \\
\hline Ensino Fundamental I & 3 \\
\hline Ensino Fundamental I, Ensino Fundamental II, Ensino Médio & 1 \\
\hline Ensino Fundamental II & 4 \\
\hline Ensino Fundamental II, Ensino Médio, Ensino Superior & 1 \\
\hline Ensino Médio & 4 \\
\hline Ensino Médio, Ensino Subsequente de nível Técnico; Ead & 1 \\
\hline Ensino Superior & 5 \\
\hline Ensino Superior, Pos graduação strictu sensu & 1 \\
\hline Não leciono & 1 \\
\hline No momento estou fora da escola & 1 \\
\hline Total Geral & 34 \\
\hline
\end{tabular}

Fonte: Dados compilados da pesquisa - este item permitiu a seleção de mais de um item.

\subsection{CONTRIBUIÇÕES DO TCC PARA A FORMAÇÃO DOCENTE}

Na produção de um trabalho de conclusão de curso a maior parte dos alunos tem medo, preocupação, dificuldades em saber lidar com as pressões de cumprimentos de prazos, choques de ideias com o seu orientador e dúvidas. Nesta questão os sujeitos informaram o quanto o TCC contribuiu para aprenderem a lidar com o lado afetivo-emocional. O Gráfico 1 apresenta o nível de contribuição relacionado ao nível de formação, pois este está associado a experiência anterior na realização de pesquisas por parte do sujeito. 
Gráfico 1 - Contribuição do TCC no desenvolvimento afetivo-emocional.

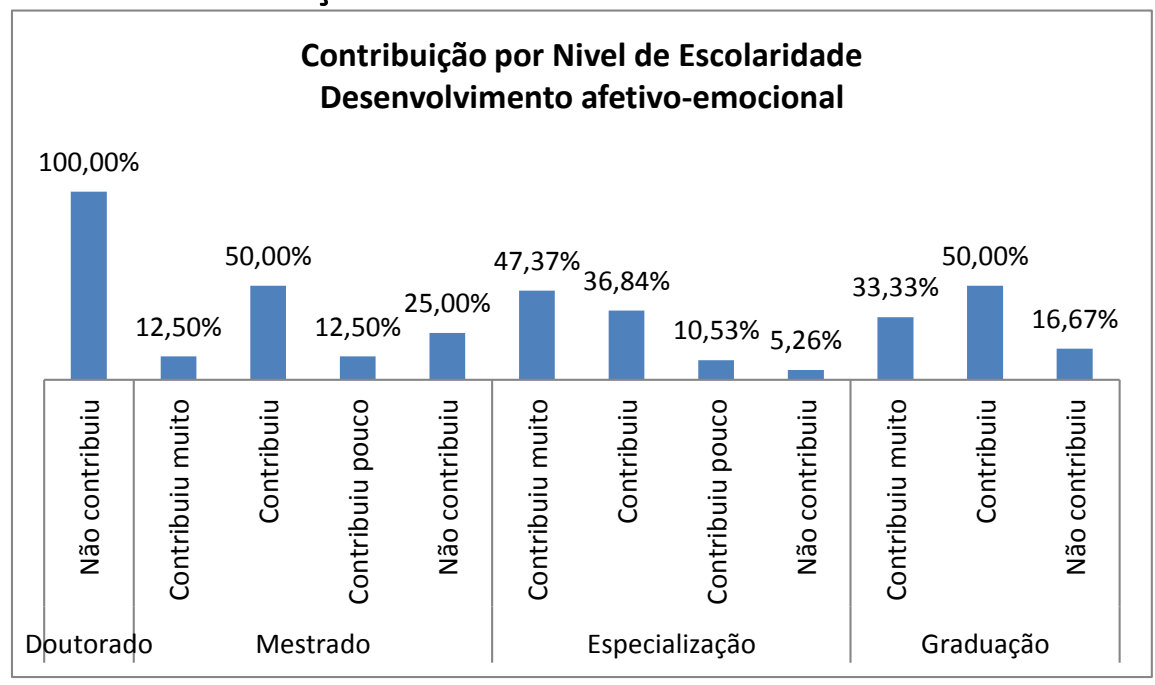

Fonte: Dados compilados da pesquisa.

Desses que responderam 35\% disseram que contribuiu muito, 41\% afirmaram que contribuiu, $9 \%$ que contribuiu pouco, $15 \%$ disseram que não contribuiu. Conforme Gráfico 1, pode-se observar que para os doutores este item não gerou contribuição, para 62,5\% dos mestres este item contribuiu muito ou contribuiu, para a maioria dos especialistas $(84,21 \%)$ e para a maioria dos graduados $(83,33 \%)$ este item contribui muito ou contribui com a sua formação.

Conforme Gráfico 2, quanto a contribuição que a construção do TCC teve em sua formação acadêmica durante a PIE, no desenvolvimento de suas habilidades (na leitura, na escrita, na solução de problemas, na organização dos dados), 41\% disseram que contribuiu, 38\% contribuiu muito, $15 \%$ contribuiu pouco, $6 \%$ não contribui. O percentual mais alto dos que disseram que contribuiu pouco, foram os sujeitos com nível de doutorado com 100\%. Pode-se afirmar que já possuem habilidades pois já passaram por várias fases de pesquisa para obter o título de doutor. $83,33 \%$ dos sujeitos com nível de graduação e 89,47\% de nível de especialização e $75 \%$ dos que possuem mestrado disseram que contribuiu e contribuiu muito para o desenvolvimento de habilidades. 
Gráfico 2 - Contribuição do TCC no desenvolvimento de habilidades.

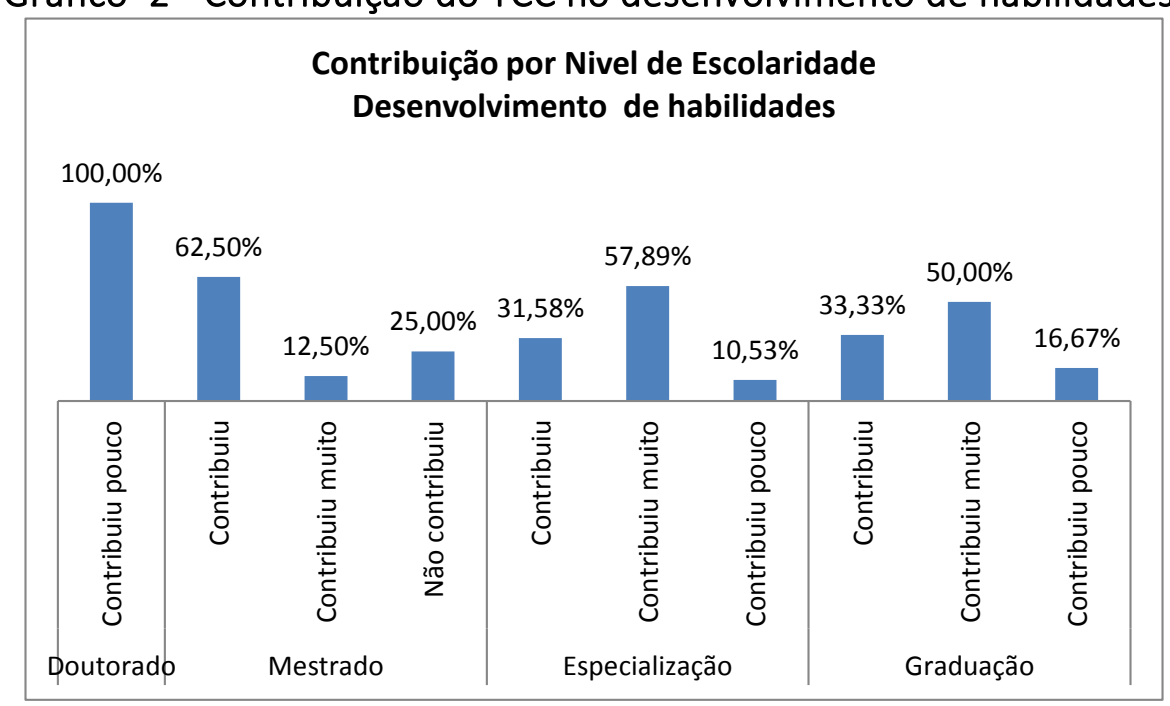

Fonte: Dados compilados da pesquisa.

Conforme Gráfico 3, foi possível também verifica a contribuição do TCC quanto a aquisição de atitudes/valores (ética no trabalho, responsabilidade, caráter). Dos sujeitos $44 \%$ disseram que contribuiu muito, 38\% contribuiu, $12 \%$ contribuiu pouco, $6 \%$ não contribuiu. Visto que a referência de atitudes e valores sofrem influência desde o início da formação. Nele percebe-se que os que já possuem nível de doutorado disseram nesta questão que o TCC, contribuiu pouco. E $25 \%$ dos que disseram que "não contribuiu" foram sujeitos com nível de mestrado.

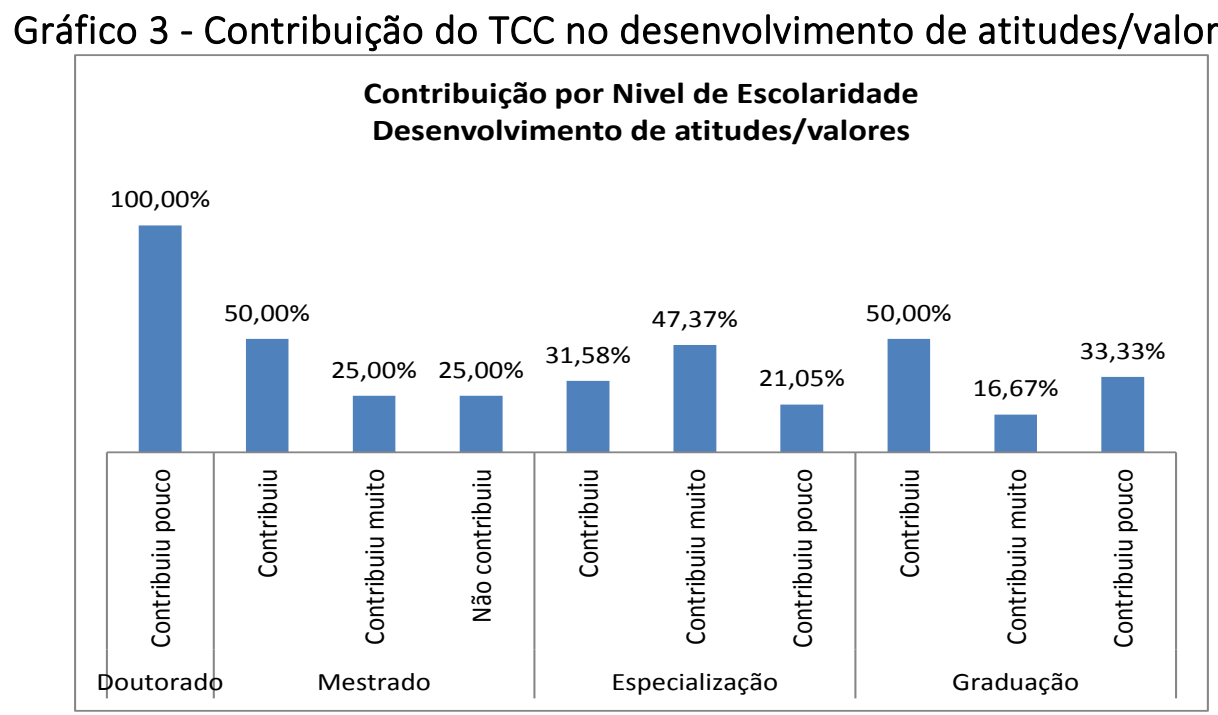

Fonte: Dados compilados da pesquisa. 
No Gráfico 3, percebe-se que os que já possuem nível de doutorado disseram nesta questão que o TCC, contribuiu pouco. E 25\% dos que disseram que "não contribuiu" foram sujeitos com nível de mestrado.

No Gráfico 4, vemos as contribuições em relação à ampliação do conhecimento Técnico adquirido durante o curso PIE. Esse consiste em um conhecimento adquirido sobre determinado assunto, objeto, e é obtido por tempo de experiência, ou seja, o individuo aprende na prática. Na pesquisa $56 \%$ disseram que contribuiu muito, a construção do TCC na formação acadêmica para a ampliação do conhecimento técnico. Dos sujeitos $26 \%$ consideram que contribuiu, $15 \%$ que contribuiu pouco, e 3\% que não contribuiu.

Visto que, o curso PIE, possui muitas atividades práticas. No Gráfico 4, temos os $12,50 \%$ que disseram que "não contribuiu" já possuem mestrado. Também foi notado que na condição de "contribuiu pouco" 50\% possuíam graduação e 10,53\% especialização.

Gráfico 4 - Contribuição do TCC no desenvolvimento de conhecimentos técnicos.

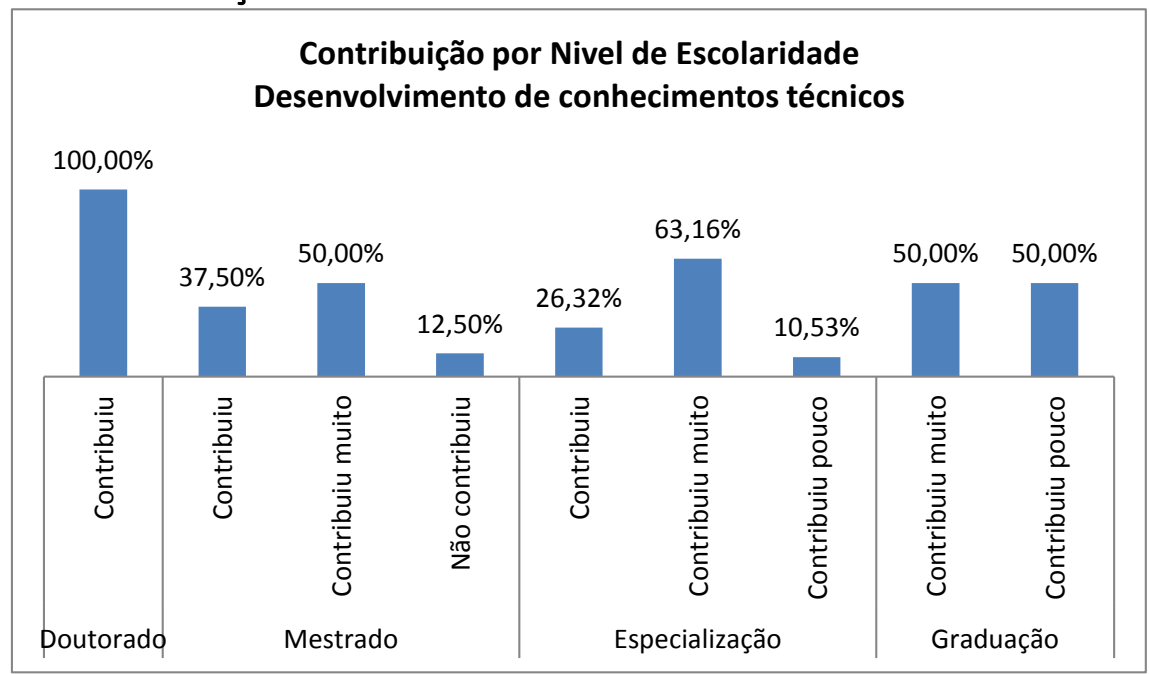

Fonte: Dados compilados da pesquisa.

No curso PIE há troca de informações e conhecimentos, mesmo sendo um curso a distância, essa proximidade com pessoas diferentes de diversas culturas, a interculturalidade, favorece ao sujeito ter novas ideias. 
Gráfico 5 - Contribuição do TCC no desenvolvimento da interculturalidade.

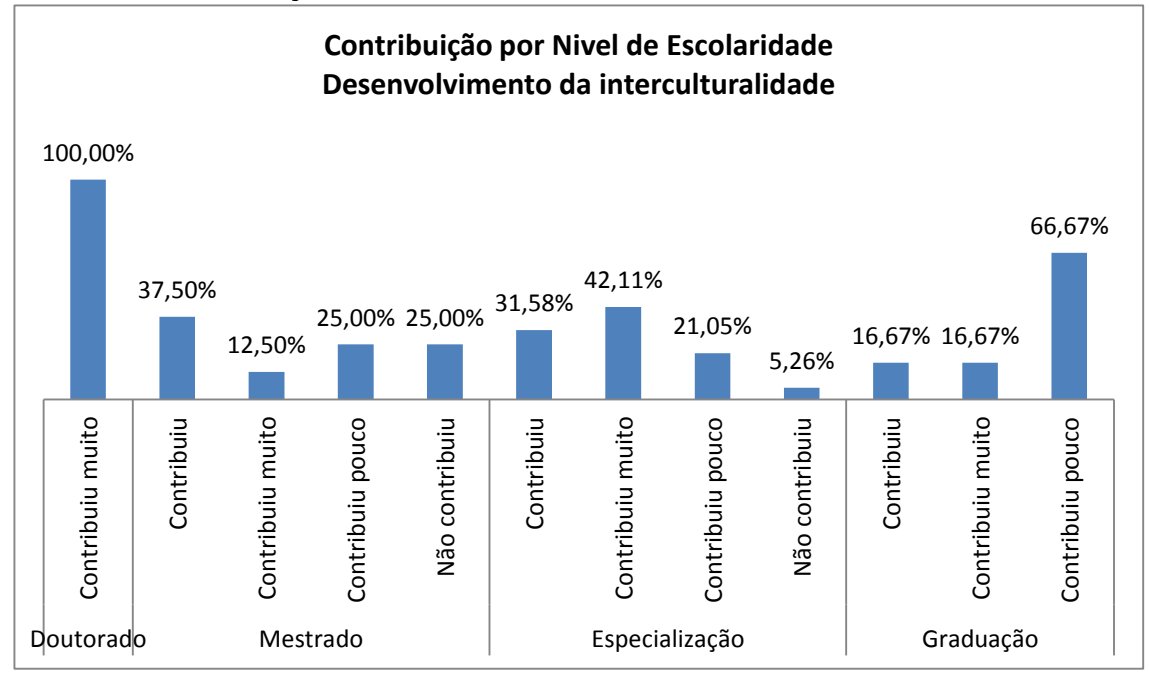

Fonte: Dados compilados da pesquisa.

No Gráfico 5, temos a contribuição do TCC no desenvolvimento dessa interculturalidade. Nele observamos que 32\% disseram que essa interação contribuiu muito, 29\% que contribuiu pouco, 9\% que não contribuiu. Dos sujeitos 66,67\% que disseram que contribuiu pouco possuem apenas graduação, e a PIE foi sua primeira experiência em pós-graduação. Dos que possuem doutorado 100\% disseram que contribuiu muito. Dos que possuem especialização 42,11\% disseram que contribuiu muito. $E$ dos que possuem mestrado $37,50 \%$ disseram que contribuiu.

As contribuições que esta etapa teve na prática docente dos sujeitos da pesquisa podem ser verificadas de forma resumida na Tabela 4.

Tabela 4 - Contribuição do TCC na Prática Docente.

\begin{tabular}{|c|c|c|c|c|c|c|c|c|c|c|}
\hline \multirow[t]{2}{*}{ Contribuição do TCC na Prática Docente } & \multicolumn{2}{|c|}{$\begin{array}{c}\text { Contribuiu } \\
\text { muito }\end{array}$} & \multicolumn{2}{|c|}{ Contribuiu } & \multicolumn{2}{|c|}{$\begin{array}{c}\text { Contribuiu } \\
\text { pouco }\end{array}$} & \multicolumn{2}{|c|}{$\begin{array}{c}\text { Não } \\
\text { contribuiu }\end{array}$} & \multicolumn{2}{|c|}{ Total } \\
\hline & Qtde & $\%$ & Qtde & $\%$ & Qtde & $\%$ & Qtde & $\%$ & Qtde & $\%$ \\
\hline orática docente & 15 & $44 \%$ & 11 & $32 \%$ & 4 & $12 \%$ & 4 & $12 \%$ & 34 & $100 \%$ \\
\hline O fez refletir sobre a sua prática docente & 20 & $60 \%$ & 7 & $20 \%$ & 4 & $10 \%$ & 3 & $10 \%$ & 34 & $100 \%$ \\
\hline Ajudou a solucionar problemas do cotidiano escolar & 10 & $29 \%$ & 10 & $29 \%$ & 8 & $24 \%$ & 6 & $18 \%$ & 34 & $100 \%$ \\
\hline O fez se interessar mais pela pesquisa científica & 15 & $44 \%$ & 13 & $38 \%$ & 3 & $9 \%$ & 3 & $9 \%$ & 34 & $100 \%$ \\
\hline $\begin{array}{l}\text { O fez pensar em continuar os estudos em níveis de } \\
\text { mestrado e doutorado }\end{array}$ & 16 & $47 \%$ & 11 & $32 \%$ & 3 & $9 \%$ & 4 & $12 \%$ & 34 & $100 \%$ \\
\hline Total & 76 & $45 \%$ & 52 & $31 \%$ & 22 & $13 \%$ & 20 & $12 \%$ & 170 & $100 \%$ \\
\hline
\end{tabular}

Fonte: Dados compilados da pesquisa. 
Na prática docente, que é recheada de desafios, $44 \%$ dos sujeitos da pesquisa afirmaram que a elaboração do TCC contribuiu muito para a prática, e 32\% disse que contribui, $12 \%$ afirmaram que contribui pouco e 12\% que não contribuiu.

Vale ressaltar que, conforme Gráfico 6, dos sujeitos que afirmaram que a produção do TCC não contribuiu para a sua prática docente somente 33,33\% teve sua pesquisa associada a prática docente, já no caso dos sujeitos que afirmaram que a produção do TCC contribuiu pouco para sua prática tivemos a distribuição igualitária quanto a associação do tema da pesquisa a sua prática docente.

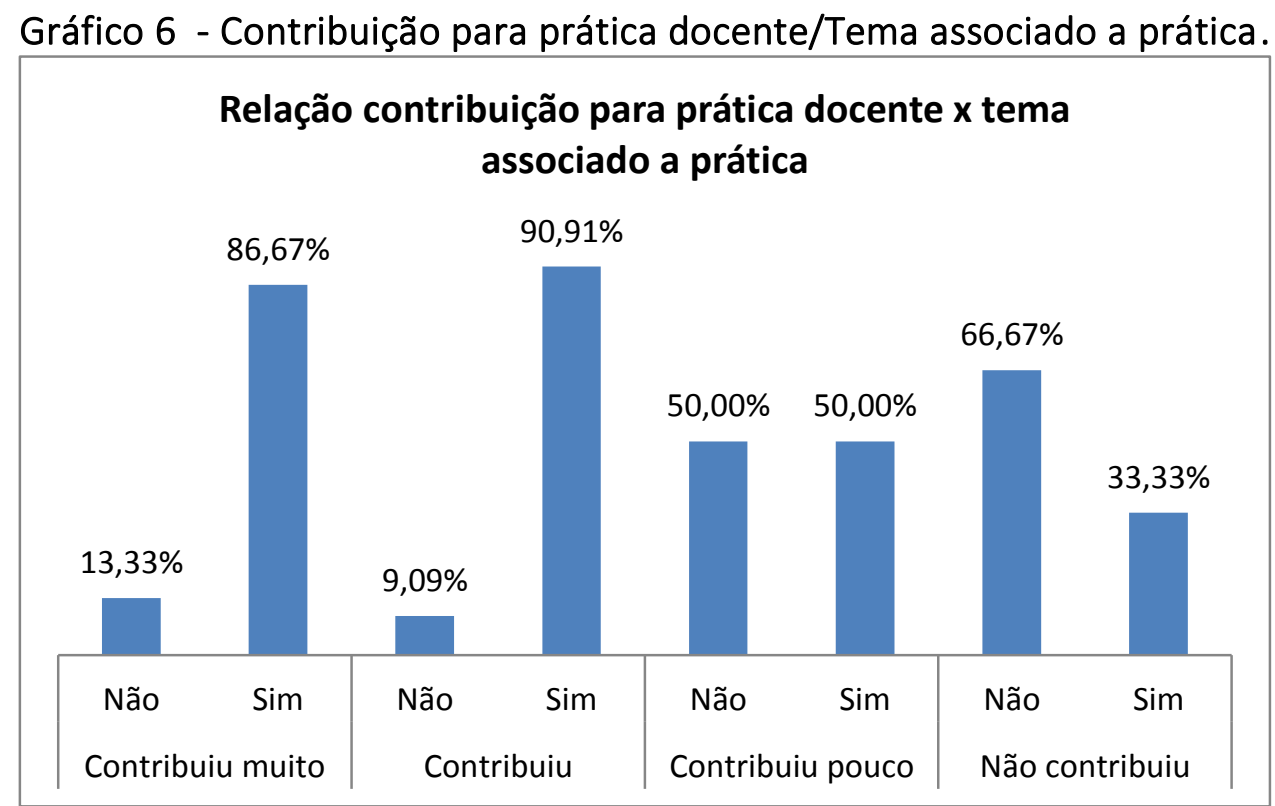

Fonte: Dados compilados da pesquisa.

Ainda no Gráfico 6, podemos observar que $86,67 \%$ disseram que a produção do TCC com tema associado a prática contribui muito com o exercício da reflexão sobre a prática.

A reflexão faz pensar, encontrar caminhos e meios para elucidar os problemas do cotidiano escolar. Por meio da pesquisa é possível descobrir problemas do cotidiano e buscar como resolvê-los. Dos sujeitos pesquisados $58 \%$ afirmam que o TCC contribuiu e contribuiu muito, para ajudar a solucionar os problemas no cotidiano escolar. 42\% afirmam que contribuiu pouco e/ou não contribuiu. 
As Instituições devem incentivar a pesquisa em toda a carreira acadêmica. Dos sujeitos pesquisados $44, \%$ disseram que a elaboração do TCC contribuiu muito com o seu interesse pela pesquisa científica, 38\% disseram que contribuiu, 9\% disseram que contribuiu pouco e 9\% disseram que a elaboração do TCC não contribuiu com o seu interesse pela pesquisa científica.

O contato com a pesquisa científica proporcionada pela elaboração do TCC fez com que $47 \%$ afirmassem que essa tarefa contribuiu muito e $32 \%$ que contribui para que os fizessem ter interesse em continuar a pesquisa em nível de mestrado e doutorado. Já 9\% afirmaram que a construção do TCC contribuiu pouco e 12\% que não contribuiu com o seu interesse em continuar os estudos em nível de mestrado e doutorado.

\subsection{ElaboraÇÃo do TCC NO CURSO PIE}

Neste item analisaremos as respostas das questões 13 a 23, das quais 2 (duas) perguntas são fechadas e 9 (nove) abertas, nas quais os sujeitos puderam expressar sua opinião.

Sobre a questão que abordou os possíveis motivos que levaram os sujeitos a escolherem o tema do TCC, quase todos responderam: usar tecnologias na escola, dificuldades dos professores com o uso de tecnologia, e melhorar a aprendizagem dos alunos com o apoio das tecnologias. Desses $75 \%$ disseram que o tema escolhido estava associado a sua prática em sala de aula.

Os temas mais escolhidos pelos sujeitos foram sobre: formação dos professores e o uso de tecnologias nas escolas. Quando do levantamento dos dados, 79,4\% defenderam o tema escolhido, $11,8 \%$ estão em fase de defesa e 5,9\% não defenderam o TCC. Desses que não defenderam o TCC apontaram a falta de apoio dos professores, bem como do orientador. Já os alunos que defenderam e estão em fase de defesa alegaram que os principais desafios e dificuldades que encontraram 
para realização do TCC foram: falta de tempo para se dedicar a pesquisa, falta de apoio dos professores e Instituições pesquisadas, bem como dificuldade com a orientação. Algumas das dificuldades apontadas podem ser reforçadas com base em algumas falas:

\section{Quadro 1 - Dificuldades Apontadas.}

Professor 14 - [...] Falta de disponibilidade por conta da carga horária extensa tanto por minha parte como dos entrevistados, falta de recursos financeiros e de uma maior presença do orientador.

Professor 21 - [...] A falta de compromisso em responder e entregar os questionários nas datas estabelecidas, enquanto uns nem entregaram.

Professor 32 - [...] O tempo foi o maior desafio, pois fiz minha pesquisa com meus alunos do 5a ano, trabalhava duas aulas com eles no laboratório de informática, pois o turno era vespertino e o laboratório ficava livre em alguns dias.

\section{Fonte: Dados da Pesquisa.}

Outra questão buscou verificar se a elaboração do TCC colaborou para resolver problemas do contexto escolar apoiadas no uso das tecnologias. Dos sujeitos 24 responderam que sim, mas ressaltaram algumas dificuldades no acesso e disponibilidade dos laboratórios. Entretanto, os alunos que estão chegando às escolas precisam ser preparados para o século XXI e o docente precisa se capacitar para atender as expectativas, o que implica no uso potencial de tecnologias na prática docente e na constante pesquisa e reflexão sobre a prática.

Após a realização do TCC buscou-se verificar quais os impactos gerados em saber pesquisar enquanto saber docente. Dos sujeitos, 26 disseram que o aprender a pesquisar contribuiu para um bom planejamento das aulas e ajudou em sua prática docente. Corroborando com Carvalho e Pérez (2011, p.59) temos que "[...] Como 
formador de pesquisadores novatos, o professor deve considerar-se corresponsável pelos resultados que estes obtiverem: não pode situar-se frente a eles, mas com eles; [...]". Conforme alguns relatos apontam, percebemos que durante a formação de professores é necessário incentivar a pesquisa.

\section{Quadro 2 - Sobre Pesquisa.}

Professor $14-[. .$.$] É necessário pesquisar sempre para assim adquirir conhecimentos e atualizar-$ se.

Professor $18-[. .$.$] O professor pesquisador tem mais chances de mudar e inspirar seus alunos. 0$ aluno tenta se espelhar em bons professores, aqueles que incentivam a reflexão e crítica.

Professor $30-[. .$.$] Consigo ver com novos olhos a tecnologia me auxiliando no processo de ensino$ aprendizagem, assim como uma melhora no desempenho e interesse dos meus discentes, após colocar em prática um pouco que foi aprendido na pesquisa feita para meu TCC.

Fonte: Dados da Pesquisa.

Na questão sobre os pontos positivos e negativos da experiência enquanto pesquisador na realização do TCC foi utilizado o recurso de nuvem de palavras para verificar a ocorrência dos principais termos. Sobre os pontos positivos, na nuvem as palavras que mais destacadas foram: pesquisa, prática, conhecer e conhecimento (Figura 1). 
Figura 1 - Nuvem de Palavras gerada pelo aplicativo Tagul a partir dos pontos positivos.

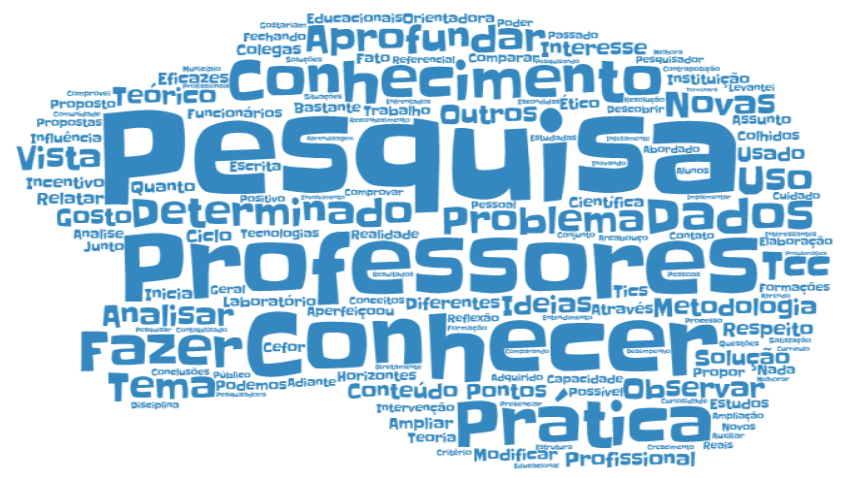

Fonte: Dados compilados da pesquisa.

Também foram citados, os pontos negativos, da experiência como pesquisador por estes sujeitos, e assim, foi gerada uma nuvem de palavras. As palavras mais citadas por eles foram: Falta e Tempo (Figura 2).

Figura 2 - Nuvem de palavras gerada pelo aplicativo Tagul a partir dos pontos negativos.

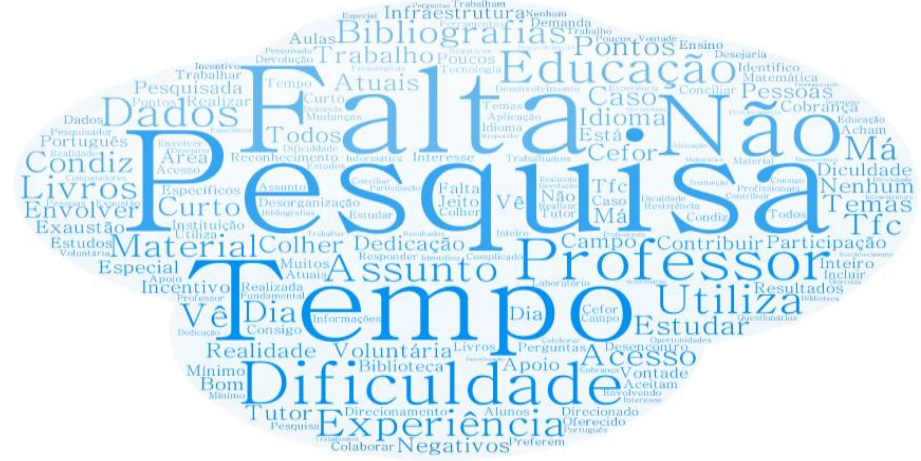

Fonte: Dados compilados da pesquisa.

Nota-se que a maior parte dos sujeitos questionou a falta de tempo e como conciliar trabalho e pesquisa, outros também alegaram dificuldade de conseguir que os professores e instituições pesquisados participassem da pesquisa.

Outra questão buscou levantar se a produção do TCC foi prazerosa. Dos sujeitos pesquisados, 21 responderam que sim, 6 disseram que não, e 2 sujeitos queriam ser melhor orientados e 1 ainda não soube responder. Visto que, a maior parte afirma que sentiu prazer na elaboração do TCC, percebe-se que os mesmos escolheram temas na área de atuação. 
No final da pesquisa foi aberto um espaço livre para que os sujeitos pudessem complementar sua opinião a respeito do tema da pesquisa "A Influência do TCC na formação Docente". Destacam-se algumas das respostas:

Quadro 3 - Influências do TCC.

Professor 17- [...] Ótima iniciativa desta pesquisa, gostei desta oportunidade de expressar minhas experiências sobre o método de TCC do IFES que infelizmente me desmotivou e fui reprovado.

Professor 22 - [...] Pesquisa boa, porém extensa.

Professor $24-[. .$.$] É necessário repensar a seriedade e o modo de se pesquisar no Ensino superior,$ por isso reflexões como essas são sempre bem-vindas.

Professor 29 - [...] Se isso virar um TCC, uma pesquisa. Quero ler! Tenho pra mim que a maioria das pessoas considera essa a pior parte do trabalho e alguns até desistem. Tiro isso pela minha atual turma do PIE.

\section{Fonte: Dados da Pesquisa.}

As opiniões quanto à aplicação deste questionário na pesquisa foram positivas, a maior parte dos pesquisados responderam que esse tipo de pesquisa é satisfatória para o aperfeiçoamento das pesquisas nos cursos de formação de professores de Instituições de Ensino Superior.

\section{CONSIDERAÇÕES FINAIS}

Essa pesquisa teve como objetivo analisar a Importância da Pesquisa, desenvolvimento do Trabalho de Conclusão de Curso, na formação docente enquanto prática reflexiva com base na percepção dos alunos do curso de Pósgraduação Lato Sensu em Informática na Educação no seu processo de aprendizagem e na sua prática docente.

Foi possível verificar que os professores estão à procura de cursos para aperfeiçoar sua prática em sala de aula. A pesquisa verificou que a maioria dos sujeitos de pesquisa são professores que já possuem especialização. Tal fato indica que muitos dos professores que estão iniciando a carreira profissional estão preocupados em especializar-se, e aqueles que já possuem especialização e 
experiência docente, optam por realizar o curso com o intuito de aprender a inserir tecnologias em suas práticas.

Por meio dessa pesquisa, foi observado que os alunos, necessitam apropriar-se do saber docente, saber pesquisar, aliado com as teorias. Esse saber leva o professor a refletir sobre a sua prática e a preparar atividades que levam a formar pessoas para o pensamento crítico. Vale ressaltar que a pesquisa é inerente a prática pedagógica reflexiva.

Quanto a elaboração do TCC, temos que torna prazerosa para professores que pesquisam algo que os inquieta, que aguça a curiosidade, e que estão relacionado a sua prática de alguma forma. Mesmo que ela seja desafiador, no final o aluno sente sensação de prazer, pelo fim de suas indagações ou até pela possibilidade de vir a dar continuidade em nível de mestrado/doutorado.

Outro aspecto relevante observado diz respeito à aprendizagem gerada por uma pesquisa, TCC, tida como satisfatória. Mas isso depende da instituição formadora, que leve o aluno por meio de pesquisa a desenvolver habilidades de escrita, leitura, organização de dados e solução de problemas. Além disso, temos o conhecimento técnico, a interculturalidade para se aperfeiçoar na pesquisa e a reflexão sobre a prática, e lidar com o lado afetivo emocional, prazo de entrega de TCC, choque de ideias e dúvidas.

Ao Iniciar essa pesquisa tivemos a intenção de entender como a produção do TCC colaborou para a prática pedagógica reflexiva e no processo de aprendizagem dos alunos do PIE. De acordo com o questionário aplicado foi observado se o tema escolhido estava relacionado à prática docente de cada aluno pesquisador.

Entendemos que realizar pesquisa/TCC é muito importante para a prática dos professores e que traz inúmeros benefícios, como preparar instituições para formar 
professores reflexivos. Além disso, a pesquisa também colabora com a resolução de problemas do contexto escolar, mas como foi dito não é redentora.

Quanto às dificuldades enfrentadas pelos alunos pesquisadores temos a falta de tempo e de apoio dos locais pesquisados, visto que a maior parte trabalha mais de 26 horas por semana. Já quanto ao apoio tecnológico, os alunos pesquisados foram unânimes em dizer que os laboratórios são precários, prejudicando a realização da pesquisa dentro da instituição em que leciona. Além disso, apontam como dificuldades: o acesso a material bibliográfico, o apoio de orientador e o cumprimento dos prazos.

Ainda assim, concluímos que os alunos pesquisados reconhecem a importância da pesquisa, como contribuição importante para o desenvolvimento do seu trabalho docente, visto que eles puderam expressar suas percepções a respeito, apresentando o quanto a pesquisa ajudou em sua prática docente.

Esta pesquisa também teve algumas observações negativas a respeito do curso PIE, no entanto foi um porcentual muito pequeno, em relação às experiências positivas. Mas tais índices estimulam o aperfeiçoamento dessa e a realização de outas pesquisas que busquem refletir sobre a importância da pesquisa na formação docente.

\section{REFERÊNCIAS}

ANDRADE, M. M. de. Introdução a Metodologia do Trabalho Científico. 6 ed. São Paulo: Atlas, 2003.

ANDRÉ, M. E. D. A. de. Ensinar a pesquisar: Como Para quê. In: VEIGA, I. P. A., (org.), Lições de Didática. Campinas -SP: Papirus, 2006, pp. 123-134. 
ANDRÉ, M. E. D. A. de. Pesquisa, Formação e Prática Docente. In: André, M. (Org.). O papel da Pesquisa na formação e na Prática dos Professores. 12 ed. Campinas-SP: Editora Papirus, 2012. p, 55-69

CARVALHO, A. M. P.; PÉREZ, D. G. Formação de professores de Ciências ( Tendências e Inovações). 10. ed. São Paulo : Cortez, 2011.

FREIRE, Paulo. Pedagogia da Autonomia Saberes Necessários à Prática Educativa. 25.ed. São Paulo: Paz e Terra, 1996.

NASCIMENTO, F.; FERNANDES, H. L.; MENDONÇA, V. M. de. O Ensino de Ciências no Brasil: História, Formação de Professores e Desafios Atuais. Revista HISTEDBR Online, Campinas, n.39, p. 225-249, set. 2010 - ISSN: 1676-2584

NOBRE, I. A. M. Docência Coletiva: saberes e fazeres na educação a distância. Tese (Doutorado) Universidade Federal do Espírito Santo Centro de Educação Programa de Pós-Graduação dm Educação. Vitória. 2013.

PERRENOUD, P. As competências para ensinar no século XXI: a formação dos professores e o desafio da avaliação. Tradução de Cláudia Schilling e Fátima Murad. Porto Alegre: Artmed, 2002.

PERRENOUD, P. Formar professores em contexto sociais e Mudanças. Prática reflexiva e participação crítica. Revista Brasileira de Educação, Set-Dez 1999, n 12, pp. 5-21.

SAMPIERI, R. H.; COLLADO, C. H.; LUCIO, P. B. Metodologia de pesquisa. Mexico: McGraw-Hill Internacional, 1991. 